University of Nebraska - Lincoln

DigitalCommons@University of Nebraska - Lincoln

2010

\title{
Morphology control of tungsten nanorods grown by glancing angle RF magnetron sputtering under variable argon pressure and flow rate
}

\author{
Khedir R. Khedir \\ University of Arkansas at Little Rock \\ Ganesh K. Kannarpady \\ University of Arkansas at Little Rock, gkkannarpady@ualr.edu \\ Hidetaka Ishihara \\ University of Arkansas at Little Rock \\ Justin Woo \\ University of Arkansas at Little Rock \\ Charles Ryerson \\ Center US Army Corps of Engineers \\ See next page for additional authors
}

Follow this and additional works at: https://digitalcommons.unl.edu/usarmyresearch

Part of the Operations Research, Systems Engineering and Industrial Engineering Commons

Khedir, Khedir R.; Kannarpady, Ganesh K.; Ishihara, Hidetaka; Woo, Justin; Ryerson, Charles; and Biris, Alexandru S., "Morphology control of tungsten nanorods grown by glancing angle RF magnetron sputtering under variable argon pressure and flow rate" (2010). US Army Research. 132.

https://digitalcommons.unl.edu/usarmyresearch/132

This Article is brought to you for free and open access by the U.S. Department of Defense at DigitalCommons@University of Nebraska - Lincoln. It has been accepted for inclusion in US Army Research by an authorized administrator of DigitalCommons@University of Nebraska - Lincoln. 


\section{Authors}

Khedir R. Khedir, Ganesh K. Kannarpady, Hidetaka Ishihara, Justin Woo, Charles Ryerson, and Alexandru S. Biris 


\title{
Morphology control of tungsten nanorods grown by glancing angle RF magnetron sputtering under variable argon pressure and flow rate
}

\author{
Khedir R. Khedir ${ }^{\mathrm{a}}$, Ganesh K. Kannarpady ${ }^{\mathrm{a}, *}$, Hidetaka Ishihara ${ }^{\mathrm{a}}$, Justin Woo ${ }^{\mathrm{a}}$, Charles Ryerson ${ }^{\mathrm{b}}$, \\ Alexandru S. Biris ${ }^{\mathrm{a}, 1}$ \\ a Nanotechnology Center, University of Arkansas at Little Rock, 2801 South University Avenue, Little Rock, AR 72204, United States \\ b Terrestrial and Cryospheric Sciences Branch Cold Regions, Research E Engineering Laboratory Engineer Research and Development, Center US Army Corps of Engineers, \\ Hanover, NH 03755-1290, United States
}

\section{A R T I C L E I N F O}

\section{Article history:}

Received 7 July 2010

Received in revised form 21 August 2010

Accepted 26 August 2010

Available online 27 August 2010

Communicated by R. Wu

\section{Keywords:}

Tungsten nanorods

Glancing angle deposition

RF magnetron sputtering

Phase transformation

Morphology control

\begin{abstract}
A B S T R A C T
Morphologically novel tungsten nanorods (WNRs) with the co-existence of two crystalline phases, $\alpha$-W (thermodynamically stable) and $\beta$-W, were fabricated by glancing angle RF magnetron sputtering technique under various Ar pressures and flow rates. For these nanorods, a significant variation in their morphology and surface roughness was observed. These structures could be useful in a wide range of applications such as field emission, robust superhydrophobic coatings, energy, and medicine.
\end{abstract}

(c) 2010 Elsevier B.V. All rights reserved.

\section{Introduction}

One-dimensional nanostructural thin films, such as nanorods, fabricated by the glancing angle deposition technique (GLAD) [1-4] have shown potential applications in a wide range of technological disciplines: in the enhancement of field ionization in pyroelectric crystal D-D nuclear fusion [5], field emission [6], superhydrophobic coatings [7], photonic crystals [8], surface enhancement Raman spectroscopy SERS [9], humidity sensors [10], thermal barrier coatings [11], and solar cells [12]. The wide range of suggested applications of these nanorods is due to their high aspect ratio of surface area to volume, anisotropy, controlled porosity, and tunable morphology.

The GLAD technique, as a Physical Vapor Deposition (PVD) method, is based on impingement of the incident flux onto the substrate from an oblique angle of $\alpha>80^{\circ}$ (the angle between substrate normal and incident flux) [1]. Azimuthal rotation of the substrate during deposition controls the uniformity and columnar

\footnotetext{
* Corresponding author. Tel.: +1 501569 8067; fax: +1 5016837601.

E-mail addresses: gkkannarpady@ualr.edu (G.K. Kannarpady), asbiris@ualr.edu (A.S. Biris).

1 Tel.: +1 501551 9067; fax: +1 5016837601 .
}

alignment, a brush-like morphology, parallel to the surface normal to the substrate alignment [4]. However, competition between limited surface adatom mobility and extreme shadowing effects play the critical roles in the evolution of the columnar structure of the thin film [13]. By varying the deposition parameters, the morphology and porosity of the nanostructural thin films for various materials have been previously investigated using both experimental and simulation approaches. For this, parameters such as substrate rotation angle $\varphi$ [14], incidence flux angle $\alpha$ [15], the ratio of substrate temperature to the materials melting point $\boldsymbol{T}_{s} / \boldsymbol{T}_{m}$ [16], and deposition rate [17] have been proven to have a significant role in the morphology of the synthesized nanostructures.

The two phases of Tungsten; the stable phase (bcc) $\alpha-\mathrm{W}$ which is thermodynamically favorable and the metastable phase (A15) $\beta$-W have different properties. The lattice parameters of the two phases are 3.16 and $5.04 \AA$ for (bcc) W and (A15) W, respectively. The electrical resistivity of $\alpha-\mathrm{W}$ is always lower than the electrical resistivity of $\beta$-W due to the larger grain size and lower oxygen concentration [18]. Related to the deposition parameters, the appearance of the two phases in the case of normal incidence thin films have been reported by some researcher [18-20]. However, in the case of GLAD, Karabacak et al. have reported only the formation of $\beta$-W phase [21]. In another study, Singh et al. [22] have shown that the WNRs with $\beta$-W phase can be used as field ion- 
izer at low operating voltage. To our knowledge, the creation of the two phases for WNRs has not been reported yet.

Resistive thermal evaporation, electron beam thermal evaporation, and sputtering methods have been extensively used to deposit nanostructural thin films using the GLAD technique. But the variation of working gas such as Ar pressure in the case of sputtering gives enhanced flexibility in tailoring certain properties of the nanostructural thin films. In addition, a wider range of materials with better film quality can be deposited using this method. The influence of Ar pressure on the morphology and deposition rate when $\alpha=0^{\circ}$ (normal incidence) is well understood. However, in the case of GLAD, very limited systematic studies have been conducted. It has been shown that an increase in pressure causes a decrease in the diameter of the nanorods and a subsequent increase in their density [23]. The Ar flow rate, which is canonically related to the $\mathrm{Ar}$ pressure, also has considerable impact on the film's properties. The only study that has addressed this parameter was conducted by Y.J. Jiang et al. [24], but at normal incidence. They observed a variation in the crystallinity of ZAO thin films deposited at various Ar flow rates. However, no studies have been performed so far that address the influence of Ar flow rates in the case of GLAD.

The wide range to technological applications of tungsten films, for example, semiconductor interconnect layers as diffusion barriers [25], X-ray mirrors [26], X-ray field as absorbing layer [27], field ionization [22], etc., has motivated us to do a study where both morphology and surface roughness of tungsten thin films can be tailored. Therefore, a systematic study was carried out to address the influence of $\mathrm{Ar}$ pressure and $\mathrm{Ar}$ flow rate on the morphology and surface roughness of WNRs. Glancing Angle RF magnetron sputtering was used to fabricate WNRs, at various Ar pressures and flow rates. To the best of our knowledge, this is the first study that reports the fabrication of WNRs with the co-existence of $\alpha-\mathrm{W}$ and $\beta$-W phases. A MATLAB program was developed to study the size distribution of WNRs employing image analysis techniques. The crystallographic phase analysis was carried out using XRD. SEM and AFM techniques were used to study the morphology and surface roughness.

\section{Experimental procedure}

\subsection{Tungsten nanorod fabrication}

In this work, the WNR films were deposited on glass substrate (size of $2.5 \mathrm{~cm} \times 2.5 \mathrm{~cm}$ ) by means of RF magnetron sputtering. After the substrates were cleaned by sonication in both acetone and methanol, each for duration of 5 minutes, they were mounted on a rotatable holder inside the chamber, $150 \mathrm{~mm}$ away from the target (Fig. 1). For GLAD, the angle between the surface normal to the substrate and surface normal to the target was $85^{\circ}$. The target was W with a purity of $99.9 \%$ purchased from ACI Alloys, Inc., USA. The pressure in the chamber was lowered using a cryo pump supported by a mechanical pump to a base pressure of less than $2.0 \times 10^{-6}$ mtorr. The substrate rotation was set to $30 \mathrm{rpm}$. Power density of $7.64 \mathrm{~W} / \mathrm{cm}^{2}$ was applied throughout the entire deposition process. To remove surface contamination of the target, it was pre-sputtered for 5 minutes onto the shutter between the substrate and the target prior to the deposition on the substrate. The depositions were carried out under four Ar pressures (0.5, 1.0, 5.0, and 10.0 mtorr) by introducing pure Ar at three different flow rates $(3,10$, and $20 \mathrm{sccm})$ under each pressure separately for $60 \mathrm{~min}$ utes. A digital mass flow rate controller was used to control the argon flow rate that introduced into the chamber through an injection gas positioned through the sheath just above the target, as shown in Fig. 1. All WNRs thin films were deposited at near room temperature without substrate heating.

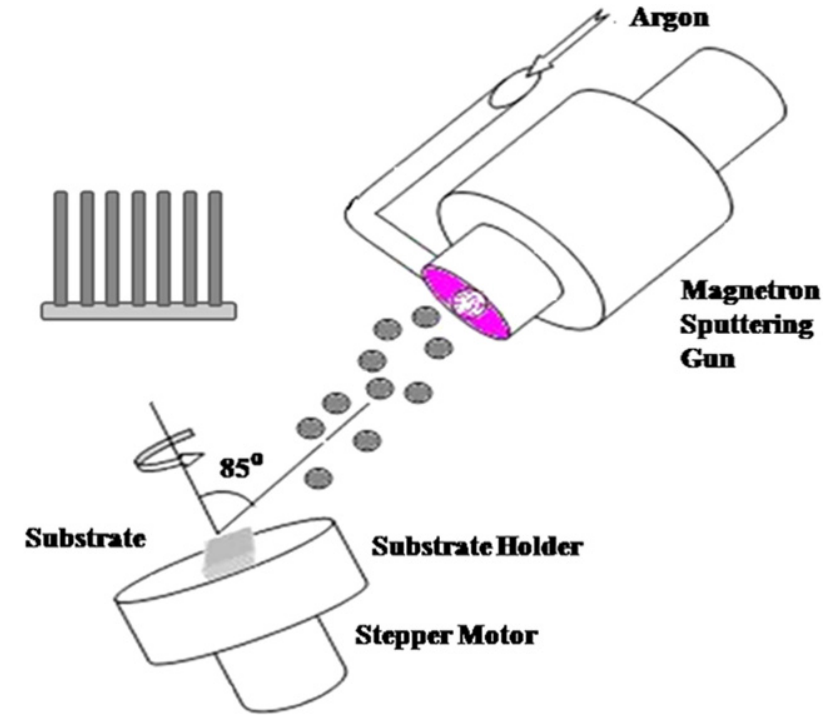

Fig. 1. Schematic diagram of GLAD using RF magnetron sputtering method.

\subsection{Topography}

To study the influence of Ar pressure with the variation of its flow rate on the size of WNRs deposited on the glass substrate, scanning electron microscopy (SEM) (JEOL SEM7000FE) was performed. The uniformity of the WNRs was investigated by taking images from three different locations which were chosen randomly over the surface of the WNRs films. The investigation of surface roughness and surface morphology was carried out by using Nanoscope 3100 Atomic Force Microscopy. Tapping mode was used to scan the surface of WNRs at three random locations. The root mean square surface roughness $R_{q}$ of the three scanned locations was compared, and a reasonable correlation among the results was achieved.

\subsection{Image analyses}

The image analysis technique was performed on the top-view SEM images of the as-deposited WNRs, using image analysis tool in MATLAB, to calculate the normal size distribution (Gaussian distribution) of WNRs. Typical image analysis steps are shown in Fig. 2. A raw SEM image as shown in Fig. 2(a) was converted into a binary image by subtracting the background (noise). This resulted in a subsequent increase in image contrast, leading to the binary image with only bright and dark areas as shown in Fig. 2(b). The bright and the dark areas were considered as the nanorods and the voids, respectively. For better accuracy in determining the size of nanorods, the nanorods located on the border of the image were eliminated, where most of them are partially appeared in the image. Also, very small areas (less than 5 pixels) with poor brightness were excluded. Because, those areas represent nanorods that have not reached the surface and they vanished during the growth competition of islands as a result of shadowing effect. These nanorods have little significance in terms of morphology and corresponding surface physical and chemical properties as their growth was completely terminated before they reach the surface.

Typically, the WNRs have pyramid shape tips $[7,21]$ as seen in Fig. 2(a). However, the rest of the nanorod body shows near circular shape. So, an assumption was made in the MATLAB mathematical code to assign a circular boundary covering the pyramid tip to measure the diameter of the nanorod. The pixel scale in image analysis was converted to nanometer scale by comparing it with the bar scale at the bottom of SEM images. An illustration of the detection of the nanorods by MATLAB code is shown in Fig. 2(c). As 

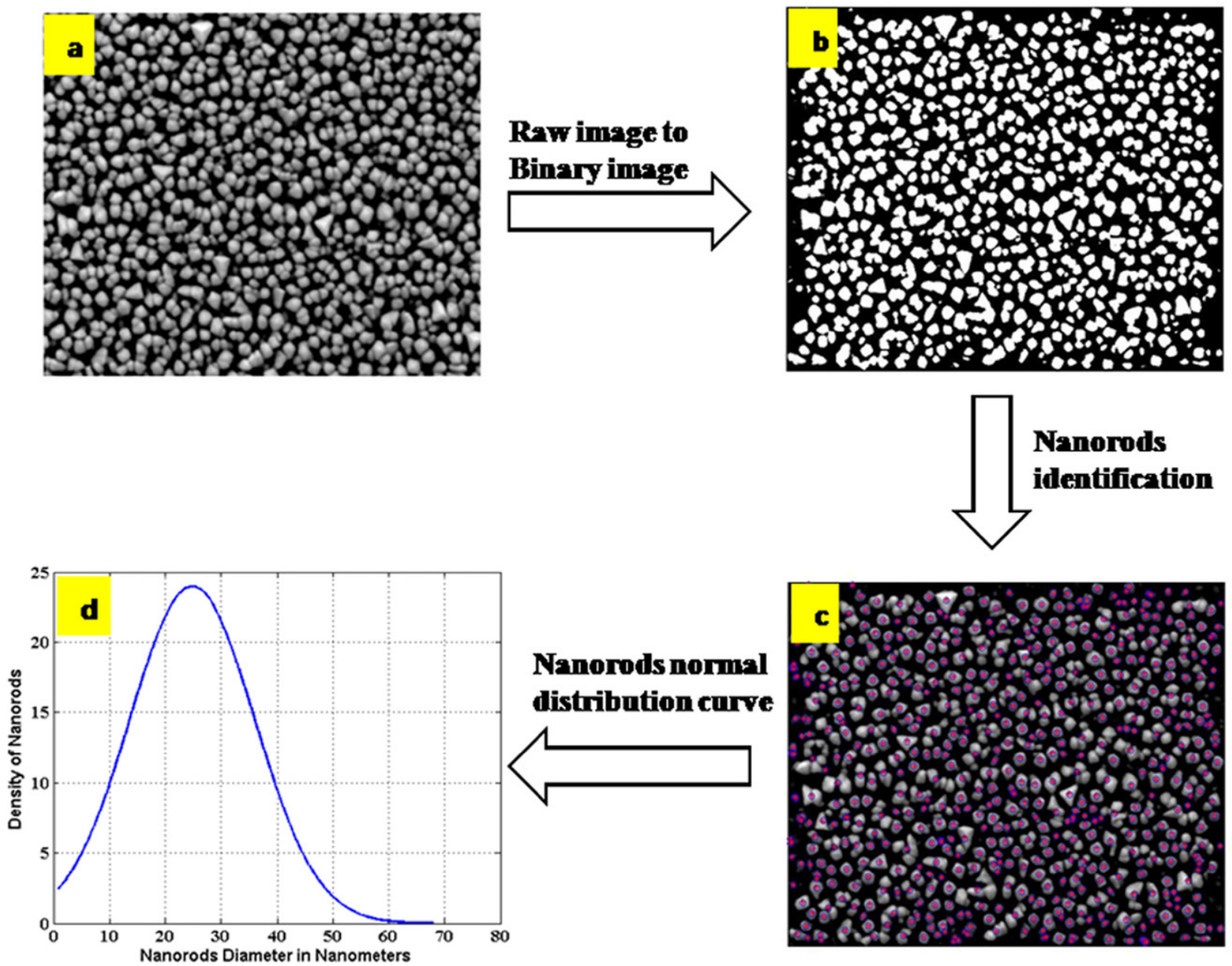

Fig. 2. Illustration of different steps involved in the image analyses technique using MATLAB to calculate normal size distribution of the nanorods.

seen in the figure more than $99.9 \%$ of nanorods have been identified by this technique. The resulted normal size distribution curve is shown in Fig. 2(d). Overall, the number of nanorods involved in the calculations per each image were ranged from 300 to 1000 depending on their density as the size of the SEM picture used for the analysis is the same in all the cases. Finally, the image analysis calculations were carried out for three SEM images that were taken at three random positions of each sample. The size distributions on three random locations of the samples have shown very good correlations indicating the nanorod distribution is highly uniform.

\subsection{X-ray diffraction XRD analyses}

X-ray diffraction XRD analyses, using a Bruker AXS D8 operating at $45 \mathrm{kV} 30 \mathrm{~mA}$ with $\mathrm{CuK}_{\alpha}$ radiation source with $\lambda=$ $1.5406 \AA$, were performed to study the crystallographic structure of WNRs thin films. Three-dimensional figures were plotted for the diffracted intensities of the peaks that achieved the Bragg condition versus $\mathrm{Ar}$ pressure and the three $\mathrm{Ar}$ flow rates of 3,10 , and $20 \mathrm{sccm}$.

\section{Results and discussions}

\subsection{The influence of Ar pressure}

Top view SEM images of the WNRs deposited under various argon pressures of $0.5,1.0,5$, and 10 mtorr and various argon flow rates of 3,10 , and $20 \mathrm{sccm}$ for each pressure separately, are shown in Fig. 3. From this figure, it can be seen that the lateral size of WNRs decreases with the increase in Ar pressure, from top to bottom, but for constant Ar flow rates. This is due to the fact that, with the increase in Ar pressure, sputtered atoms will undergo more and more scattering with plasma's constituents, which in turn causes a broadening in the angular distribution of sputtered atoms and a decrease in their mean free paths. Consequently, the sputtered atoms can reach the shadowed areas and increase the density of nucleation sites on the substrate. Moreover, at high deposition pressures, namely 5 to 10 mtorr, the WNRs begin to attach to each other creating bundles of WNRs at 5 mtorr and more significantly at 10 mtorr. Yanhong Ma et al. [23] reported similar trends for Silicon nanorods (SiNRs) deposited by the GLAD technique. The surface roughness was also enhanced with the increase in Ar pressure as shown in Table 1. At high Ar pressure of 5 and 10 mtorr, compared to low Ar pressures of 0.5 and 1.0 mtorr, lower deposition rates would be obtained. The higher rate of scattering between the sputtered atoms and $\mathrm{Ar}$ atoms at high pressures causes lower rates of sputtered atoms to reach the substrate. Consequently, the sputtered atoms have enough time to diffuse over the surface, without being masked by the incoming atoms. Large features, WNRs bunches, and larger voids can be seen in the case of WNRs deposited at high pressures of 5 and 10 mtorr, as illustrated in Fig. 3, without being densely packed. The influence of the deposition rate on the surface roughness of $\mathrm{Cu}$ sculptured thin films has been investigated by $\mathrm{H}$. Savaloni et al. [17]. They have 


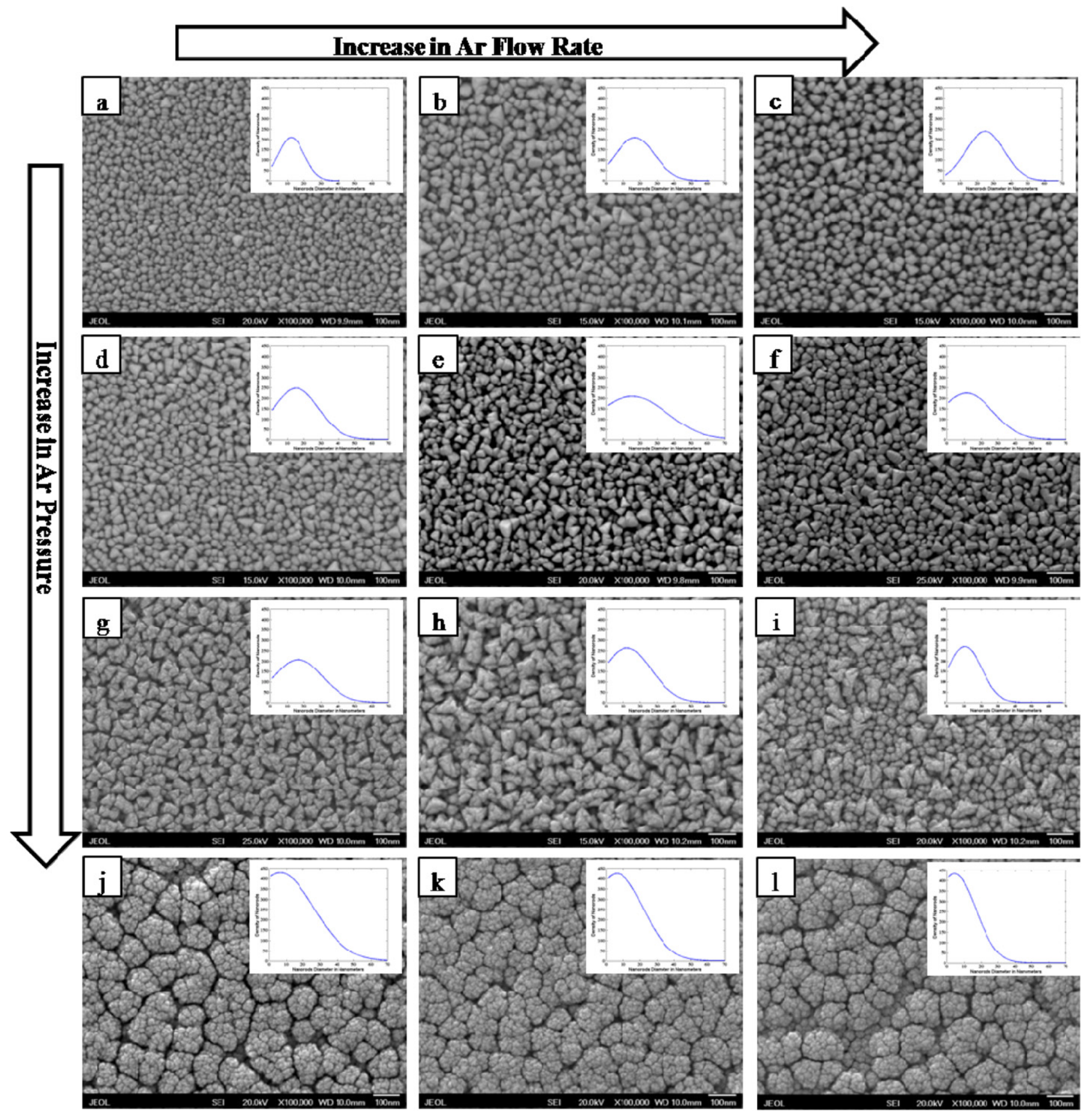

Fig. 3. Top-view SEM images and Gaussian distribution for WNRs grown at [(a), (b), and (c)] 0.5 mtorr with Ar flow rates (3, 10, and $20 \mathrm{sccm}$, respectively), [(d), (e), and (f)] 1.0 mtorr with Ar flow rates (3, 10, and $20 \mathrm{sccm}$, respectively), [(g), (h), and (i)] 5.0 mtorr with Ar flow rates (3, 10, and 20 sccm, respectively), [(j), (k), and (l)] $10 \mathrm{mtorr}$ with Ar flow rates $(3,10$, and $20 \mathrm{sccm}$, respectively). All the insets are in the same scale (X axis: nanorod diameter (nm), full scale 0-70; Y axis: density of nanorods, full scale $0-450$ ).

Table 1

Root mean square surface roughness of the as-deposited WNRs under various Ar pressures and Ar flow rates.

\begin{tabular}{|c|c|c|c|c|c|c|c|c|c|c|c|c|}
\hline Ar pressure (mtorr) & 0.5 & & & 1.0 & & & 5.0 & & & 10.0 & & \\
\hline Ar flow rate $(\mathrm{sccm})$ & 3 & 10 & 20 & 3 & 10 & 20 & 3 & 10 & 20 & 3 & 10 & 20 \\
\hline$R_{q}(\mathrm{~nm})$ & 2.41 & 2.37 & 2.31 & 2.024 & 2.44 & 2.43 & 5.24 & 6.01 & 5.89 & 8.02 & 5.77 & 6.63 \\
\hline
\end{tabular}

shown that an increase in deposition rate leads to a decrease in the degree of surface roughness.

Fig. 3 is the three-dimensional XRD characterization of WNRs that deposited at various Ar pressures of $0.5,1.0,5.0$, and 10 mtorr with three Ar flow rates of 3, 10, and $20 \mathrm{sccm}$ for each pressure separately. It was shown that the metastable phase of WNRs $\beta$-W, with crystal orientation of (210) and (400), is predominant at low Ar pressure with constant Ar flow rates. However, WNRs 
(a) 0.5 mtorr

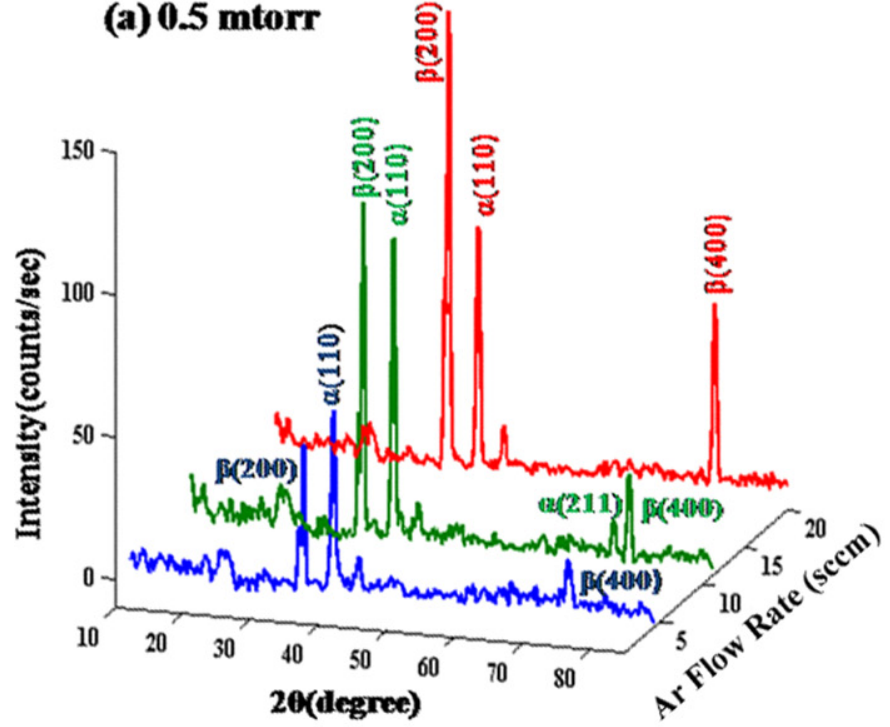

(c) 5 mtorr

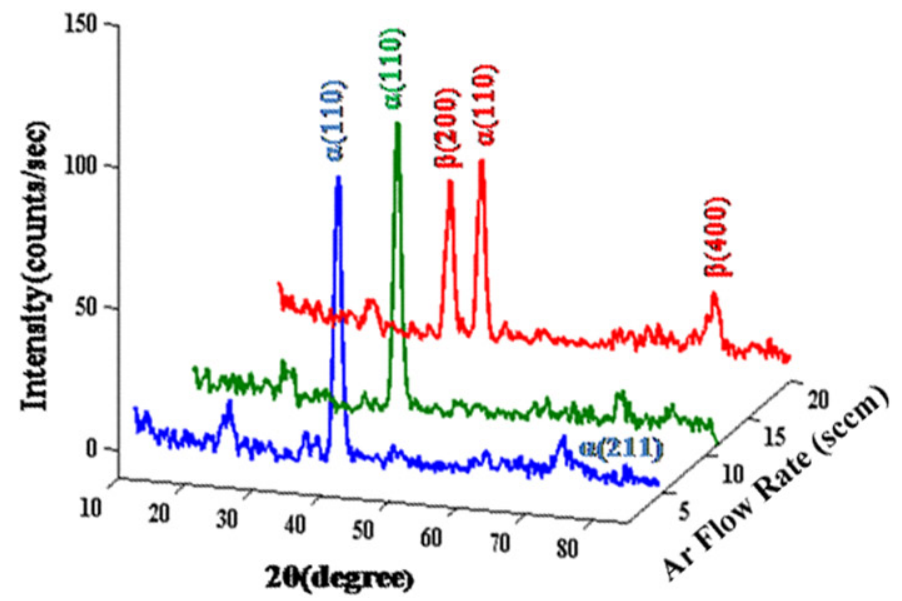

(b) 1.0 mtorr

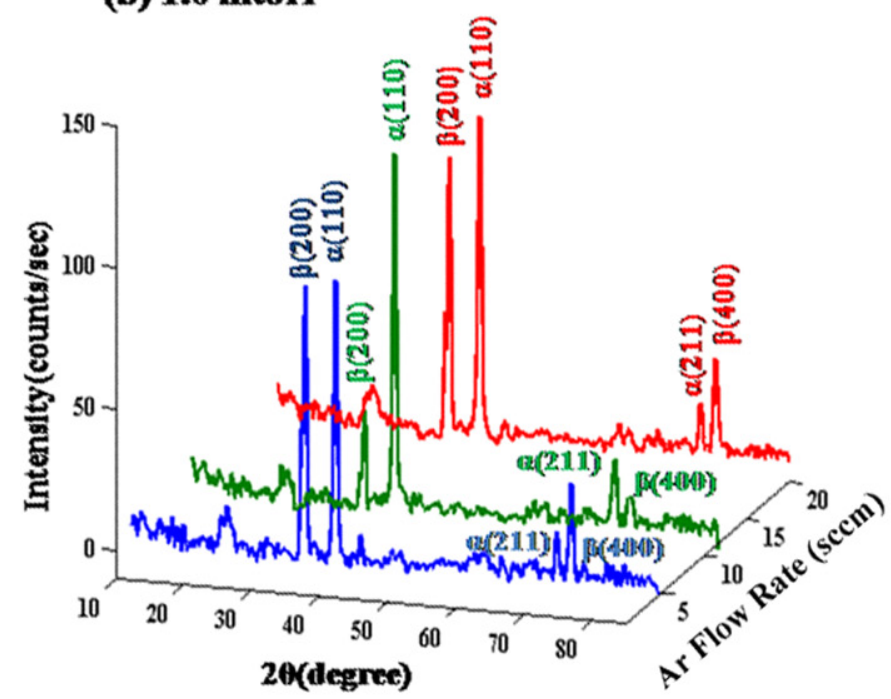

(d) 10 mtorr

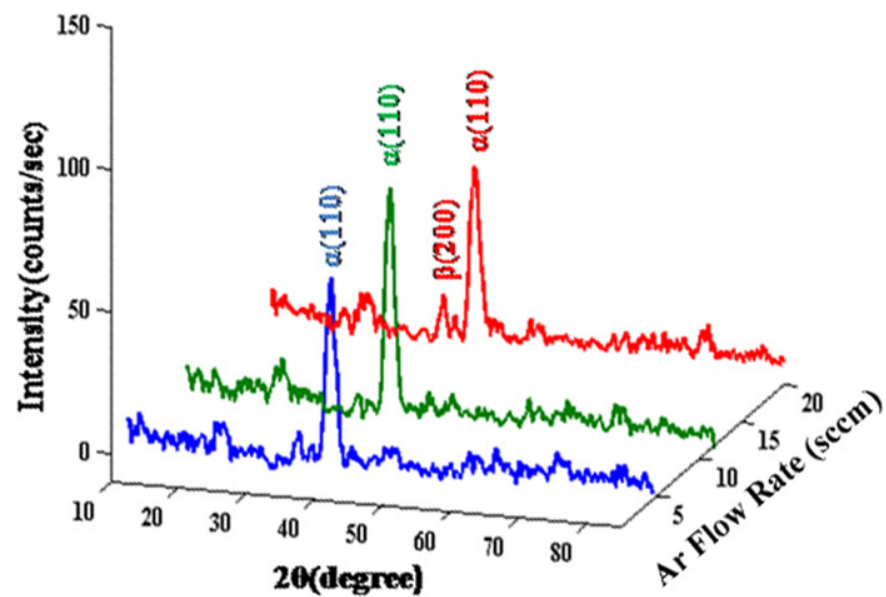

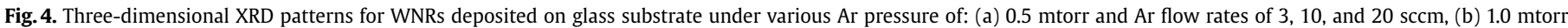
and Ar flow rates of 3, 10, and $20 \mathrm{sccm}$, (c) 5.0 mtorr and Ar flow rates of 3, 10, and $20 \mathrm{sccm}$, (d) 10 mtorr and Ar flow rates of 3, 10 , and $20 \mathrm{sccm}$.

that deposited at high Ar pressure of 5 and 10 mtorr exhibit the Tungsten stable phase $\alpha-\mathrm{W}$ with the (110) peak. This phenomenon could be due to the fact that, at low Ar pressures and because of lower density of WNRs, the oxygen atoms have larger incorporation in interstitial positions at the boundaries of WNRs. But the case is opposite at high Ar pressures, where the WNRs have higher densities to the extent of producing the glomeration of the WNRs. Karabacak et al. [21] have reported the creation of $\beta$-W phase in the case of GLAD and $\alpha-\mathrm{W}$ phase in the films deposited at normal flux incidence, both depositions being conducted at relatively low Ar pressure. However, the competition between the two phases is also reported in the case of thin films deposited at normal flux incidence. Djerdj et al. [19] have observed that the increase in Ar pressure causes an increase in lattice parameters and eventually the dominance of tungsten metastable phase. They suggested that this phase transformation is due to the incorporation of both $\mathrm{Ar}$ and $\mathrm{W}$ atoms in interstitial positions. In addition, it can be noticed from Fig. 4 that the crystallinity of WNRs diminishes with the increase in Ar pressure. Eventually, at very high Ar pressures, amorphous thin films would be obtained. The increase in the deposition pressure enhances the density of nucleates formed on the substrate which diminishes the adatom mobility. Eventually, there would not be enough kinetic energy for sputtered atoms that have undergone more frequent scattering with Ar atoms before reaching the substrate to be arranged in thermodynamically preferred crystallinity. The same trend has also been confirmed for some other materials, such as $\mathrm{Cu}$, in the case of normal flux incidence [28].

In this work, which is the fabrication of WNRs at glancing angle instead of normal flux incidence, the evolution of crystallographic phases can be explained more practically in terms of competition between shadowing effect and adatom mobility. Fundamentally, it is well known that the thin film crystallographic phases are highly dependent on the deposition conditions. In the case of sputtering the sputtered atoms inherit high kinetic energy from accelerated $\mathrm{Ar}$ ions impinged on the target. Consequently, the deposited atoms on the substrate have high surface adatom mobility to compete with the shadowing effect. The competition promotes the growth of nanorods with composite phase ( $\alpha$-W and $\beta$-W) with different crystal orientations. Therefore, at low Ar pressures of 0.5 and 
1.0 mtorr and various Ar flow rates the existence of the composite phase and different crystal planes is quite significant. With the increase in Ar pressure the sputtered atoms undergo more collisions with the plasma constituents that in turn cause a decrease in the kinetic energy of the deposited atoms. The less energized atoms mostly to stabilize on the substrate thermodynamically, leading to the stable phase $\alpha-\mathrm{W}$ with smaller crystal parameters.

\subsection{The influence of Ar flow rates}

Fig. 3 shows Top view SEM images of WNRs deposited on glass substrate under various Ar pressures of $0.5,1.0,5$, and $10 \mathrm{mtorr}$, arranged from top to bottom, respectively, by introducing three different Ar flow rates of 3, 10, and $20 \mathrm{sccm}$ for each pressure separately, arranged from left to right, respectively. The normal distributions of the diameter of WNRs for all the top view SEM images are also inset in Fig. 3. It can be seen that their morphology is significantly affected by the variation of Ar flow rates, particularly at low pressures. The Gaussian distribution of the size of WNRs, deposited at constant pressure of 0.5 mtorr but differing Ar flow rates of 3,10, and $20 \mathrm{sccm}$, reveals that the WNRs' diameter increases from 12 to 18 and then to $25 \mathrm{~nm}$, respectively. For the WNRs that were deposited at constant 1 mtorr pressure and various $\mathrm{Ar}$ flow rates of 3 , and 10, the diameters increased from 16 to $18 \mathrm{~nm}$, respectively, except for WNRs deposited at Ar flow rate of $20 \mathrm{sccm}$, where their diameters decreased to $12 \mathrm{~nm}$. However, at the high pressures of 5.0 and 10 mtorr, the opposite scenario occurs. At 5.0 mtorr, the diameter of WNRs deposited at Ar flow rates of 3,10 , and $20 \mathrm{sccm}$ are 18,14 , and $10 \mathrm{~nm}$, respectively. WNRs deposited at 10 mtorr with Ar flow rates of 3, 10, and $20 \mathrm{sccm}$ have the average diameters of 10,8 , and $5 \mathrm{~nm}$, respectively.

The three-dimensional XRD graphs depicted in Fig. 4 demonstrate the competition between the two phases of tungsten which is more predominant at low Ar pressures. WNRs deposited at the constant Ar pressure of 0.5 mtorr but various Ar flow rates prefer the metastable phase $\beta$-W with the dominant peak of (200). The competition is comparable for WNRs deposited at a constant Ar pressure of 1 mtorr with the increase of the Ar flow rates. In the case of $10 \mathrm{sccm}$, the stable phase $\alpha-\mathrm{W}$ with the (110) peak is dominant. At relatively high Ar pressures of 5 and 10 mtorr, the thermodynamically preferred phase $\alpha-\mathrm{W}$ is predominant with the same peak of (110). At low deposition pressure values, the deposition rate increases with the increase in Ar flow rates, and the concrete evidence for this hypothesis is the bias voltage. At low pressures of 0.5 and 1.0 mtorr, the bias voltage drops dramatically with the increase of flow rates but remains almost stable at high pressures of 5 and 10 mtorr, as shown in Fig. 5. Generally, the decrease of bias voltage at constant power means that the $\mathrm{Ar}$ ion conductivity is enhanced by the increase in the density of $\mathrm{Ar}$ ions and subsequent increase in the deposition rate. Therefore, with the increase in deposition rate, the diffused atoms would be masked by the incoming atoms before getting the chance to be positioned at low energy positions (thermodynamically more favorable situations). In addition, the increase in Ar flow rates in the case of low Ar pressure increases the rate of Ar atoms' incorporation into the interstitial positions. For WNRs deposited at high Ar pressures of 5 and 10 mtorr, the influence of Ar flow rate is very poor. This can be noticed from the bias voltage values which remain almost constant. This means that the increase in the flow rate of $\mathrm{Ar}$ at high pressures makes no contribution to Ar ion conductivity and deposition rate. To the best of our knowledge, the only study that has been performed to illustrate the influence of Ar flow rate on the thin film properties was conducted by Y.J. Jiang et al. [24]. In that study, under normal flux incidence, it was shown that the increase in Ar flow rate causes the lattice distortion residual stress of the film.

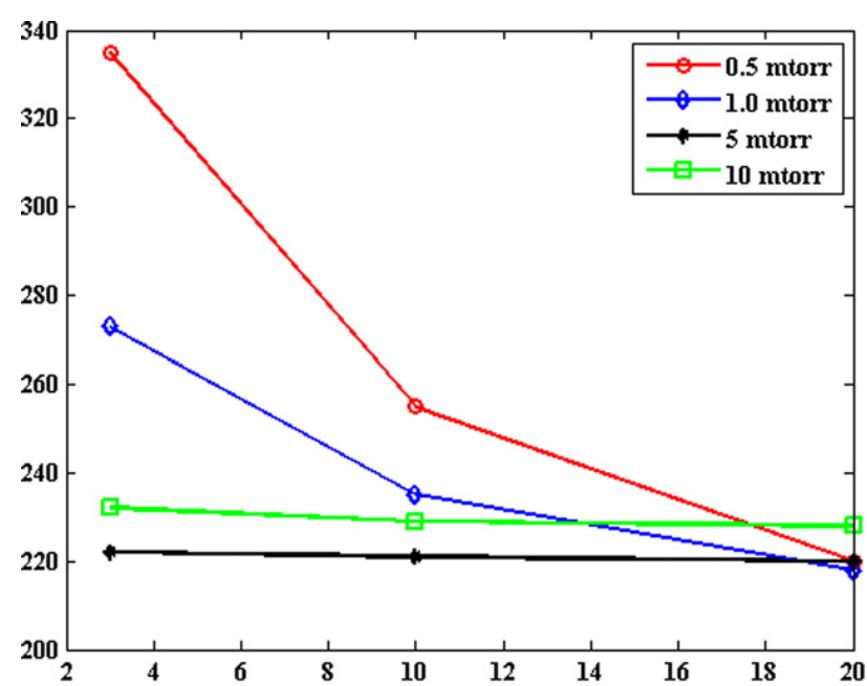

Fig. 5. Bias voltage variation with the increase in Ar flow rates.

The AFM images depicted in Fig. 6 show the influence of variation of both $\mathrm{Ar}$ pressures and $\mathrm{Ar}$ flow rates on the surface morphology of WNRs. The surface roughness $R_{q}$ of WNRs film increases from 2.02 to $8.02 \mathrm{~nm}$ with the increase of Ar pressure from 0.5 to 10 mtorr. As mentioned above, the increase in Ar pressure causes a decrease in the deposition rate [29]. Also, the sputtered atoms don't have enough kinetic energy (decrease in mean free path due to large number of collision with $\mathrm{Ar}$ atoms) to diffuse over the surface and fill the voids. On the other hand, the surface roughness $R_{q}$ as the function of Ar flow rates decreased with the increase in Ar flow rates. This can be attributed to the increase in the deposition rate at low pressures and the increase in the density of WNRs at high pressures. In both cases, the WNRs would be packed more densely compared to their counterparts.

\section{Conclusions}

The morphology and surface roughness of WNRs fabricated on glass substrate by RF magnetron sputtering, employing the GLAD technique, were tailored by the variation of pressure and flow rate of the working Ar gas. The co-existence of the two phases of WNRs, $\alpha-\mathrm{W}$ and $\beta-\mathrm{W}$, was observed for the first time to the best of our knowledge. At low Ar pressures the two phases were in competition with the variation of Ar flow rate but the stable phase, $\alpha-\mathrm{W}$, significantly dominated at high Ar pressures. It was observed that the appearance of the two phases is highly dependent on the competition between shadowing and adatom mobility in addition to the rate of incorporation of both oxygen and $\mathrm{Ar}$ atoms in the interstitial positions during the deposition. Therefore, we can conclude that the creation of a particular phase is correlated to the variation in the deposition working gas pressure and flow rate. Pressure increase resulted in a decrease in the size of WNRs and an increase in their density. The surface roughness of the WNRs was enhanced by the increase in Ar pressure. However, the opposite trend was noticed when the Ar flow rate increases at constant $\mathrm{Ar}$ pressures. In addition, the increase in $\mathrm{Ar}$ flow rates at low $\mathrm{Ar}$ pressures increases the $\mathrm{Ar}$ ion density and then enhances the ion current conductivity with a consequent increase in the deposition rates.

\section{Acknowledgements}

Financial support from US Army (ERDC Cooperative Agreement Number: W912HZ-09-02-0008), Arkansas Science \& Technology 

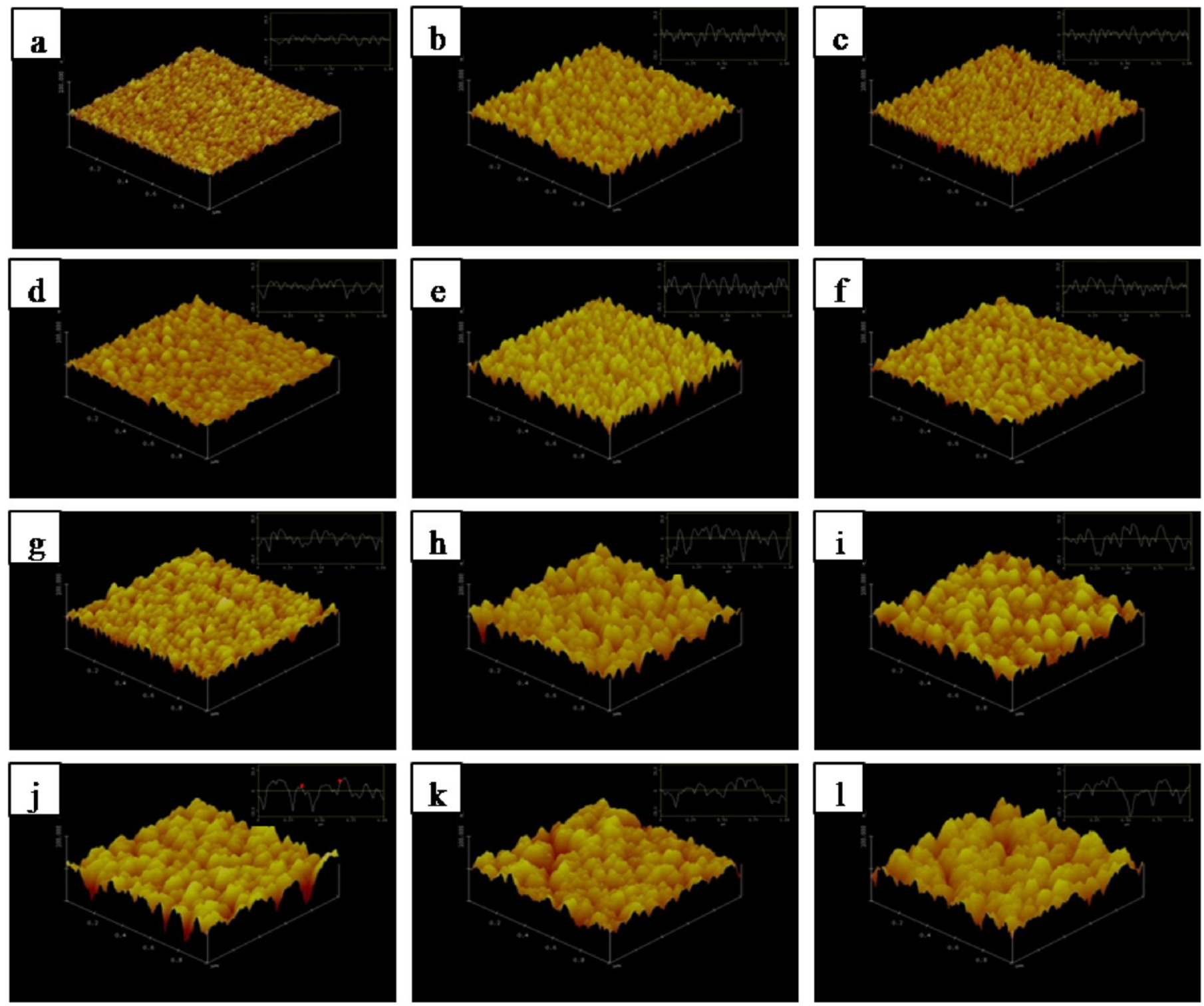

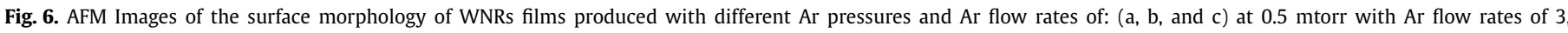

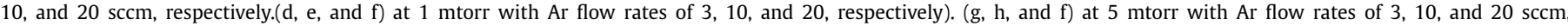

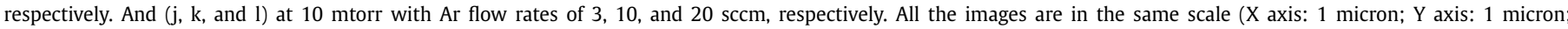
$\mathrm{Z}$ axis: $100 \mathrm{~nm}$ ).

Authority (Grant \# 08-CAT-03), and Department of Energy (DEFG36-06G086072) is greatly appreciated.

\section{References}

[1] K. Robbie, L.J. Friedrich, S.K. Dew, T. Smy, M.J. Brett, Journal of Vacuum Science \& Technology A (Vacuum, Surfaces and Films) 13 (1995) 1032.

[2] K. Robbie, M.J. Brett, Journal of Vacuum Science \& Technology A (Vacuum, Surfaces and Films) 15 (1997) 1460.

[3] M.J. Brett, M.W. Seto, J.C. Sit, K.D. Harris, D. Vick, K. Robbie, Proceedings of the SPIE - The International Society for Optical Engineering 3790 (1999) 114

[4] K. Robbie, C. Shafail, M.J. Brett, J. Mater. Res. 14 (1999) 3158.

[5] D.J. Gillich, R. Teki, T.Z. Fullem, A. Kovanen, E. Blain, D.B. Chrisey, T. Lu, Y. Danon, Nano Today 4 (2009) 227.

[6] M. Colgan, Thin Solid Films 389 (2001) 1.

[7] G.K. Kannarpady, R. Sharma, B. Liu, S. Trigwell, C. Ryerson, A.S. Biris, Appl. Surf. Sci. 256 (2010) 1679.

[8] S.R. Kennedy, M.O. Jensen, M.J. Brett, in: Proceedings International Conference on MEMS, NANO and Smart Systems, 2003, p. 165.

[9] M. Suzuki, W. Maekita, Y. Wada, K. Nagai, K. Nakajima, K. Kimura, T. Fukuoka, Y. Mori, Nanotechnology 19 (2008) 265304.

[10] M.T. Taschuk, J.B. Sorge, J.J. Steele, M.J. Brett, IEEE Sensors Journal 8 (2008) 1521.
[11] K.D. Harris, D. Vick, E.J. Gonzalez, T. Smy, K. Robbie, M.J. Brett, Surf. Coat. Technol. 138 (2001) 185

[12] Y. Ma, F. Liu, M. Zhu, J. Liu, Y. Yang, Y. Li, Z. Zhang, in: 34th IEEE Photovoltaic Specialists Conference, PVSC, 2009, p. 3

[13] D. Vick, L.J. Friedrich, S.K. Dew, M.J. Brett, K. Robbie, M. Seto, T. Smy, Thin Solid Films 339 (1999) 88.

[14] B. Dick, M.J. Brett, T. Smy, Journal of Vacuum Science \& Technology B (Microelectronics and Nanometer Structures) 21 (2003) 2569.

[15] D.-X. Ye, Y.-P. Zhao, G.-R. Yang, Y.-G. Zhao, G.-C. Wang, T.-M. Lu, Nanotechnology 13 (2002) 615.

[16] S. Mukherjee, D. Gall, Appl. Phys. Lett. 95 (2009) 173106.

[17] H. Savaloni, F. Babaei, S. Song, F. Placido, Appl. Surf. Sci. 255 (2009) 8041.

[18] M.J. O’Keefe, J.T. Grant, J.S. Solomon, J. Electron. Mater. 24 (1995) 961.

[19] I. Djerdj, A.M. Tonejc, A. Tonejc, N. Radic, Vacuum 80 (2005) 151.

[20] H.L. Sun, Z.X. Song, D.G. Guo, F. Ma, K.W. Xu, Journal of Materials Science and Technology 26 (2010) 87

[21] T. Karabacak, A. Mallikarjunan, J.P. Singh, D. Ye, Gwo-Ching Wang, Toh-Ming Lu, Appl. Phys. Lett. 83 (2003) 3096

[22] J.P. Singh, T. Karabacak, T.-M. Lu, G.-C. Wang, N. Koratkar, Appl. Phys. Lett. 85 (2004) 3226.

[23] Y. Ma, F. Liu, M. Zhu, J. Liu, Huan-hua Wang, Y. Yang, Y. Li, Nanotechnology 20 (2009) 275201

[24] Y.J. Jiang, D.X. Zhang, H.K. Cai, K. Tao, Y. Xue, Y.P. Sui, L.S. Wang, J.F. Zhao, J. Wang, Journal of Physics: Conference Series 152 (2009) 012030. 
[25] S.M. Rossnagel, I.C. Noyan, C. Cabral, Journal of Vacuum Science \& Technology B (Microelectronics and Nanometer Structures) 20 (2002) 2047.

[26] M.S. Aouadi, R.R. Parsons, P.C. Wong, K.A.R. Mitchell, Journal of Vacuum Science \& Technology A (Vacuum, Surfaces and Films) 10 (1992) 273.

[27] M. Itoh, M. Hori, S. Nadahara, Journal of Vacuum Science \& Technology B
(Microelectronics Processing and Phenomena) 9 (1991) 149.

[28] K.Y. Chan, B.S. Teo, IET Science, Measurement \& Technology 1 (2007)

[29] J.C. Helmer, C.E. Wickersham, Journal of Vacuum Science \& Technology A (Vacuum, Surfaces and Films) 4 (1986) 408. 